before the society, and assurance that communications will receive proper attention. Such special discussions will add greatly to the interest of the meetings and to the development of truth. They will be conducted, it need not be said, with that observance of courtesy and mutual consideration which have always characterized the proceedings of this society. It will assist the chairman greatly in the arrangement of business if gentlemen will inform him at the earliest moment of their intention to make communications, or to exhibit specimens of importance, and of course it is not intended that formal papers and discussions shall prevent the freest presentation of incidental communications and general debate. I would suggest, finally, the propriety of changing the hour of meeting hereafter to 7.30 o'clock.

These words were spoken twenty-one years ago. The burst of scientific enthusiasm, the enormous progress in all branches of medical work which have occupied the last two decades here in Boston, tell their own tale.

Unfortunately, perhaps, for the completeness of our Records, much of the best work done in Boston in recent years does not appear in our Transactions. The rise of new societies, local and national, has drawn away from us numbers of epoch-making papers. But many remain to illustrate our annals. Ilere are a few, hastily gleaned from the Records: In 1873 Dr. Cheever showed how the knee-joint may be opened for a loose body. In 1874 Dr. Thomas Dwight described his well-known method of freezing sections. In 1880 Dr. Hodges read his classical monograph on pilonidal sinus. In this year, also, Dr. Whittemore read a most valuable article on dispensary abuse - the first one published among us. In 1881 Dr. John Homans read his first series of ovariotomies, Dr. James J. Putnam his well-known article on locomotor-ataxia, and Dr. Hodges on railway spine. In this year, also, Dr. Calvin Ellis made his last public communication, "On the significance of albuminuria as a symptom." During these years of the early eighties Dr. Homans constantly addressed the society on the subject of abdominal surgery, and illustrated the feasibility of laparotomy for other than ovarian disease. In 1887 Dr. Ernst's paper on "rabies" is conspicuous. In 1889 Dr. Henry J. Bigelow appeared for the last time before the society to read an account of his identification of the famous Paré portrait. The extremely interesting series of debates on appendicitis began in 1887, and has lasted even to the present time, the early participants being Drs. Fitz, Cabot, Porter, Warren, Gay, Richardson, Homans, Elliot, Watson, and many others. Perhaps the most interesting and conspicuous meeting of the period was that of Novem- ber 19, 1890, a memorial to Henry J. Bigelow. The profession gathered en masse to honor that distinguished man, then recently dead; addresses were made by R. M. Hodges, $O$. W. Holmes, Henry Iee, D. W. Cheever, Hasket Derby ; and letters were read from R. II. Fitz and $\Lambda$. T. Cabot.

Thus we come down to the last event of importance which concerns us as a society - the uniting with the Boston Society for Medical Observation in 1894. Perhaps many of us have already forgotten the existence of that most useful organization. Founded in 1835, by the younger members of the profession, it continued in active, separate existence for almost sixty years; until, finally, its objects, practices and membership became so nearly identical with those of the Improvement Society that it was deemed best to unite the two under the title of the older organization. And we now here represent these two famous institutions.

So much for our story as I read it in 7 our Records. Eighteen manuscript volumes: numberless printed transactions and papers, taken from the Americun Journal of the Medical Sciences, and the Boston Medical and Surgical Journal, tell it in exhaustive detail. Its rolls are adorned with famous names. Its purposes have been of the highest. Its vigor has been wonderfully maintained throughout the years. In this society alone is there room for many men of many minds. Here all branches of medical science may be discussed and special research popularized. Here are brought the questions of broadest interest; public hygiene, medical education, medical and surgical advance in diagnosis and treatment, and numerous other matters in which every educated physician should take an active interest.

With such a past, then, and such evidence of present vigor, let us believe that the Improvement Society may impress itself on the future and the coming century.

\section{Original Ilrtidteg.}

\section{NOTES FRON THE NEUROLOGICAL DE- PARTMENT OF THE MASSACHUSETTS GENERAI IIOSPITAI.}

\section{Sudien (Apoplectifory) Belibar Pajalisis; Hemipiagia ; Astereognosis.}

$$
\text { BY W. F. rALL. M.D., BOSTON. }
$$

Louisa II., fifty-one years old, came to the clinic; in Dr. Walton's service. Eleven years ago she was suddenly unable to talk, but in a brief time the disability disappeared, leaving no traces of the attack. A year later, when the patient was fortyone years of age, speech was arrested in the middle of a sentence, she felt dizzy, and the left arm became numb and powerless. Consciousness was retained, vision was not disturbed and there was no vomiting. She could not talk plainly, and was unable to whistle. There was drooling, and on one or two occasions liquids returned through the nose. The left arm continued numb but gradually regained power. At the end of three months she was up and about with some improvement in all her symptoms. $\Lambda$ t no time have the symptoms grown worse.

Today, ten years after the attack, she talks in a mumbling fashion, unable to enunciate clearly any word in her ordinary speech. She cannot whistle, and she drools on her pillow at night. 
There is no regurgitation of liquids through the nose. The left arm feels somewhat numb, deadlike, and the left hand cannot be used in buttoning, lacing shoes, or for the finer manipulations. There is no history of involvement of cranial nerves other than the hypoglossal and facial, nor was any history of impairment of motion of the left leg obtained, though the examination indicated some lessening of sensation of the sole.

Examination. - She was well nourished, ruddy, and clear in mind. There was typical bulbar speech; at rest the lips appeared flaccid; and puckering, compression, and separation of the lips were impossible except in very slight degree. The risorius muscles, the zygomatici, and other muscles supplied by the seventh nerves were normal on both sides. The tongue could be protruded without deviation a little beyond the lower lip, but the tip could not be directed toward the upper teeth or palate. It was impossible to groove the tongue. The palate reflex was normal; and no sensory disturbance could be discovered in the cranial nerves. The left hand could not make fine movements but the grasp seemed as strong as on the right. Tactile sensation was slightly blunted over the hand and fore-arm; at least the answer always was that the horse-hair and wisp of cotton felt plainer on the right. Pain sense (the skin was pinched) was decidedly blunted over the left hand, arm, shoulder and side of the neck, though not lost. The warm and cold test tubes were correctly named each time. Space sense was not lost, but it was impaired, as the points used required wider separation to be recognized as two on the left palm and dorsum; and the answers were less prompt. Pressure sense was altered as metallic substances were called soft. There was preservation of muscle sense, and localization of areas touched was perfect. Objects - a fifty-cent piece, a key, a knife - were unrecognized in the left hand, but were accurately named when in the right hand. The shape of a round tape measure and a fifty-cent coin could not be described, and both were called soft when placed in the left palm. Fibrillation was absent and atrophy in moderate degree was observed only in the lips and tongue. The knee jerks were normal, there was no ankle clonus, the plantar reflex was absent in both feet, but the stimulation was not felt as plainly on the left sole as the right; the pupils were equal and reacted to light and accommodation. The visual fields were not limited. Nothing abnormal appeared in the examination of the heart and urine. The arteries were not remarkable.

The symptoms of this case, apart from the paresis of the arm, are those of ordinary bulbar paralysis; the peculiarity, on account of which the case is put on record, lies in the mode of onset. The most common type of bulbar palsy is of insidious origin and gradual progression; next in frequency comes the so-called polioencephalitis inferior, which may be acute or subacute, and either come to a standstill or progress; of great rarity are the cases of apoplectiform onset and bilateral lesion in which the palsy may progress or become stationary after more or less improvement. The case reported falls in the last category, and gives no history of change in the bulbar symptoms after the improvement in the first two months of the palsy. The danger of the future, however, lies in the possibility of further degenerative changes, which may begin at any time.

The nerve supply of the orbicularis oris is derived from the facial, but there is good reason to believe the nuclear origin of this supply is from the hypoglossal, either by fibres going to the facial nucleus or entering the facial nerve. "The transverse fibres of the tongue and the orbicularis oris can only contract together."1 Further, "the orbicularis is always involved in degenerative disease of the hypoglossal nucleus, and escapes in disease of the chief nucleus of the facial." 2

The labiolingual paralysis in the case reported may perhaps best be interpreted as depending solely on a lesion of the hypoglossal nuclei. It is difficult otherwise to account for the limited facial paralysis.

In the examination the sole of the left foot was much less sensitive to stimulation than the right, an indication that the lower extremity was affected by the original lesion, though no motor loss exists in the leg at the present time. The left arm recovered in large measure from the initial paralysis, but objects are unrecognized when placed in the hand. The existence of hemiplegia and astereognosis are complications of the bulbar palsy difficult to explain in a consideration of the pathology. Gowers ${ }^{3}$ states that "These cases of sudden bulbar paralysis, it is probable, depend on softening from vascular occlusion," and adds, "There may be weakness of the limbs or an affection of sensibility, usually in the form of subjective sensations, rarely actual anesthesia." He does not, however, describe a case the parallel of the one under consideration in motor loss and sensory disturbance. It would seem that the lesion extended to the median fillet and pyramidal tract of the right side of the medulla.

\section{INTESTINAL ANASTOMOSIS.}

BY Chakles G. CUMstox, M.D., Bostox.

THe question of intestinal anastomosis being a subject of great importance and interest to modern surgeons, it may not be a loss of time to examine the work done in this line by the older surgeons.

In reading a work of great merit, well worthy of the attention of surgeons of the present enlightened times, by the famous Ambroise Bertrandi, entitled "Traité des Operations de Chirurgie," published in Paris in 1769, I was much interested in his really remarkable chapter on hernia.

In it he says, in speaking of the manner of

1 Gowers' Diseases of the Nervous System, Vol. II, p. 50.

Vol. II, p. 563 .

3 Diseases of the Nervous System, Vol. II, p. 574, 